\title{
OBLIGACIONES GENERALES DE INFORMACIÓN EN LA NUEVA REGULACIÓN ESPAÑOLA DE DISTRIBUCIÓN DE SEGUROS
}

\author{
GENERAL OBLIGATIONS OF INFORMATION IN \\ THE NEW SPANISH REGULATION OF INSURANCE \\ DISTRIBUTION
}

\author{
MARÍA JESÚS PEÑAS MOYANO* \\ Fecha de recepción: 3 de junio de 2019 \\ Fecha de aceptación 30 julio de 2019 \\ Disponible en línea: 15 de septiembre de 2019
}

Para citar este artículo/To cite this article

Peñas Moyano, María Jesús, Obligaciones generales de información en la nueva regulación española de distribución de seguros, 50 Rev.Ibero-Latinoam.Seguros, 37-81 (2019). https://doi.org/10.11144/Javeriana.ris50.ogin

doi:10.11144/Javeriana.ris50.ogin

\footnotetext{
Doctora en Derecho por la Universidad de Valladolid (1996), ORCID: https://orcid.org/0000-00016768-5241. Profesora Titular de Derecho Mercantil y Catedrática acreditada. Ha impartido conferencias y Cursos de Postgrado en varias Universidades españolas, europeas (Lille, Lisboa, Coimbra, Roma, Lecce, Bari, Trento, Pavía, Cerdeña...) e iberoamericanas (Bolivia, Nicaragua) y participado en Congresos relativos a la Unión Europea, Mercosur, Derecho concursal, Sociedades, Banca y Seguros y contratación mercantil. Ha intervenido en varios Proyectos de Investigación financiados por la Junta de Castilla y León y el Ministerio de Economía y Competitividad. Contacto: chus@eco.uva.es
} 


\section{RESUMEN}

La transposición de la Directiva (UE) 2016/97 del Parlamento Europeo y del Consejo, de 20 de enero de 2016 (IDMII) al Derecho español precisa de la elaboración de una norma nueva que recoja las novedades de esta directiva. Entre ellas destacan las nuevas obligaciones generales de información que se imponen a los distribuidores de seguros, considerando la amplitud subjetiva con la que ha de manejarse este grupo de actores en el mercado. Especial relevancia alcanza la información relativa a la remuneración a percibir, así como evitar los posibles conflictos de interés que puedan surgir. Igualmente, hay que hacer mención en el ámbito de los seguros distintos de vida a la implantación del documento de información previa, conocido por sus siglas como IPID.

Palabras Clave: Distribución de seguros; obligaciones de información; documento de información previa. 


\begin{abstract}
The transposition of Directive (EU) 2016/97 of the European Parliament and of the Council, from January 20, 2016 (IDMII) to Spanish law requires the elaboration of a new law which reflects the novelties of this directive. Among them, stands out the new general information obligations which are imposed on insurance distributors, considering the subjective breadth with which this group of actors in the market has to operate. Especially relevant is the information regarding the remuneration to be received, as well as avoiding possible conflicts of interest that may arise. Likewise, mention must be made in the field of life insurance to the implementation of the prior information document, known by its initials as IPID.
\end{abstract}

Keywords: Insurance distribution; information obligations; Insurance Product Information Document.

\title{
SUMARIO
}

1. LA OBLIGACIÓN DE INFORMACIÓN COMO PRINCIPIO BÁSICO DE LA NUEVA REGULACIÓN ESPAÑOLA DE DISTRIBUCIÓN DE SEGUROS - 2. OBLIGACIONES GENERALES DE INFORMACIÓN DE LOS DISTRIBUIDORES DE SEGUROS - 2.1. Contenido de la obligación de información - 2.1.1. Principio general - 2.1.2. Publicidad. Remuneración y conflictos de interés - 2.2. Sujetos obligados - 2.2.1. Mediadores de seguros - 2.2.2. Entidades aseguradoras - 2.2.3. Comparadores de seguros - 2.3. Modalidades de transmisión de la información - 3. INFORMACIÓN GENERAL PREVIA A PROPORCIONAR POR EL MEDIADOR DE SEGUROS: ESPECIAL REFERENCIA A LA CONDICIÓN DEL MEDIADOR Y A LA REMUNERACIÓN - 4. INFORMACIÓN GENERAL PREVIA A PROPORCIONAR POR LA ENTIDAD ASEGURADORA - 5. INFORMACIÓN Y ASESORAMIENTO PREVIOS SOBRE EL CONTRATO DE SEGURO-5.1. Aspectos generales-5.2. Tipos de venta: venta informada y venta asesorada - 6. DEBER GENERAL DE INFORMACIÓN PREVIA SOBRE EL CONTRATO DE SEGURO DISTINTO AL SEGURO DE VIDA: DOCUMENTO DE INFORMACIÓN PREVIA (IPID) - 6.1. Contenido del IPID - 6.2. Presentación e iconos - 6.3. Lenguaje y extensión 7. EXENCIÓN DE LA OBLIGACIÓN DE INFORMACIÓN PREVIA - 8. INCUMPLIMIENTO DE LA OBLIGACIÓN GENERAL DE INFORMAR - CONSIDERACIONES FINALES - BIBLIOGRAFÍA UTILIZADA ABREVIATURAS. 



\section{LA OBLIGACIÓN DE INFORMACIÓN COMO PRINCIPIO BÁSICO DE LA NUEVA REGULACIÓN ESPAÑOLA DE DISTRIBUCIÓN DE SEGUROS}

La aprobación de la Directiva (UE) 2016/97 del Parlamento Europeo y del Consejo, de 20 de enero de 2016, sobre la distribución de seguros (versión refundida) (IMD II), que busca una armonización en las disposiciones nacionales relativas al acceso y ejercicio de la actividad de distribución de seguros y reaseguros, ha dado paso a la elaboración de una nueva Ley de Distribución de Seguros y Reaseguros Privados para incorporar y actualizar esta materia en su conjunto y que, al menos de momento, se ha quedado en el Proyecto de Ley (PLDSRP), de 21 de mayo de 2018, que antes de la disolución de las Cortes Generales pasó por un amplio periodo de enmiendas que no han afectado a la materia que se va a tratar. Esta transposición se realiza también en cuestiones no requeridas por Europa ${ }^{1}$, aunque este no es el caso en materia de obligaciones de información y normas de conducta ${ }^{2}$, exigidas directamente por la norma con un refuerzo de las exigencias en esta materia, que pone de manifiesto una vez más la importancia de la transparencia informativa en el sector asegurador.

La información se convierte en una herramienta clave y de probada eficacia para conseguir el objetivo de incrementar la protección de los

1 DÍAZ LLAVONA, C., "Borrador de la futura ley de distribución de seguros: más allá de la mera transposición de la directiva. Algunas valoraciones jurídicas iniciales”, Diario La Ley, no 8951 , de 29 de marzo de 2017, pp. 1 y 2. En opinión de la autora, la realización de otras reformas del Derecho nacional no exigidas desde Europa alteraría, en caso de su puesta en marcha, el modelo actualmente vigente sin demasiada justificación y con consecuencias que tal vez no se hayan calculado de forma correcta. Junto a ello, añade, que no se procede a la reforma de cuestiones que no estaban resueltas de modo satisfactorio en la LMSRP, habiéndose perdido una oportunidad a este respecto, entre ellas, una de gran trascendencia como es la elaboración de una regulación contractual para los mediadores de diverso tipo, que no se contempla en la nueva Ley y que obligan a seguir acudiendo a la Ley 12/1992, sobre contrato de agencia o al régimen del contrato de comisión del Código de Comercio, normas que no solucionan los problemas puestos de manifiesto reiteradamente en la práctica. Tampoco se ha acometido una regulación de los compradores de seguros ni de las agencias de suscripción, ni de otras posibles figuras contractuales de colaboración y distribución. MUÑOZ PAREDES, J. Ma, "La responsabilidad de los distribuidores en el Anteproyecto de Ley de Distribución”, RES, nºs. 171-172, 2017, pp. 362 y 363.

2 El contenido de la Disposición transitoria cuarta del PLDSRP lo pone de manifiesto: Régimen de adaptación a las nuevas obligaciones de información y normas de conducta. "Los distribuidores de seguros dispondrán de un plazo máximo de tres meses a partir de la entrada en vigor de esta ley para cumplir las obligaciones de información y las normas de conducta reguladas en el capítulo VI del título II. En tanto no cumplan dichas obligaciones y normas, deberán cumplir las establecidas en el artículo 42 de la Ley 26/2006, de 17 de julio." 
clientes de productos de seguro, haciéndolo además de modo equilibrado cualquiera que sea el canal de distribución elegido para celebrar el contrato de seguro y frente a los posibles conflictos de intereses que puedan surgir, pues precisamente, a través del refuerzo de las obligaciones de información se persigue proteger al cliente asegurado frente a esos conflictos. ${ }^{-}$

Se mantiene, pues, en un puesto central de esta disciplina la obligación de informar a los asegurados a la hora de celebrar un contrato de seguro, imponiendo nuevas obligaciones, fundamentalmente de carácter previo, precontractual, con el objetivo de que el asegurado pueda prestar correctamente su consentimiento al contrato. Estas obligaciones persiguen el incremento de la transparencia en el mercado de seguros como garantía de confianza, estabilidad y buena comercialización de los productos, en línea con el resto de mercados financieros ${ }^{4}$, y tratando de revertir en lo posible la característica y aún constante asimetría informativa en la que se encuentran las contrapartes contractuales en estas relaciones a través del mayor conocimiento del cliente por parte del distribuidor.

Este posicionamiento es sin duda de fundamental importancia para seguir insistiendo en la mejora de la protección de esta parte del contrato considerada en sentido amplio, pero no puede dejarse a un lado que se están incluyendo también las obligaciones de información de las entidades aseguradoras frente al cliente asegurado cuando actúen directamente como distribuidores de seguros y que al formar parte de la oferta y conclusión del contrato de seguro, como en ocasiones ya se ha señalado ${ }^{\underline{5}}$, tal vez hubiera sido más oportuno

3 QUINTANS EIRÁS, R., "Información y conflicto de intereses en la comercialización de seguros", en GIRGADO PERANDONES, P., (Dir), El contrato de seguro en la encrucijada, Thomson Reuters Aranzadi, Madrid, 2018, p. 195. Igualmente, "Información como motor de la protección del asegurado en la comercialización de seguros”, RES, nº 175, 2018, p. 376.

$4 \quad$ No en vano, la reforma de IDM I y la correspondiente elaboración de IDM II se hizo de forma coherente con otras políticas de la Unión Europea, englobándose esta reforma en el diseño de una mayor protección de los consumidores de servicios financieros. Vid., QUINTÁNS EIRAS, Ma R., "De la mediación a la distribución de seguros: la nueva Directiva 2016/1997", Revista General de Derecho Europeo, nº 39, 2016, p. 2. Igualmente, SÁNCHEZ SANTIAGO, J. y CID BLASCO, T., "La nueva propuesta de Directiva de mediación de seguros y su impacto en el mercado español”, Papeles de la Fundación, Fundación de Estudios Financieros, nº 48, 2013, pp. 117 y ss.

5 MUÑOZ PAREDES, J. Ma, RES, nos. 171-172, 2017, p. 362. PEÑAS MOYANO, M.J., "El deber general de información de los aseguradores a los tomadores, asegurados y beneficiarios", RES, nos. 171-172, 2017, pp. 327 y 328 y n. 13. QUINTANS EIRÁS, R., "Información y conflicto de intereses...", cit., pp. 204 y 205 y RES, nº 175, p. 384. 
incluirlas en la Ley 50/1980, de 8 de octubre, de contrato de seguro (LCS).

Sin embargo, en un afán de establecer unas condiciones de competencia equitativas para los diversos operadores del sector adecuadas a todos los canales de distribución, evitar restricciones en su actividad, y lograr al tiempo que todos ellos se vean incentivados a cumplir con la normativa dispuesta, el deber de información al cliente de productos de seguros por parte de todos los distribuidores se regula en la nueva Ley. Se trata de una regulación amplia y detallada dispuesta en diversos apartados produciéndose, en definitiva, una ampliación del número de datos que deben transmitirse al cliente, lo que pone de manifiesto las múltiples aristas que la componen, ya que es fundamental, por un lado, que el cliente comprenda el producto que va a adquirir a través del conocimiento de su contenido, pero también a quién se lo compra y qué le puede exigir. ${ }^{-}$En concreto, se pormenoriza la información general previa a proporcionar por el mediador de seguros; también la información previa a proporcionar por la entidad aseguradora cuando actúe como distribuidor; la información y asesoramiento igualmente anteriores a la suscripción del contrato y el documento de información previa en el contrato de seguro distinto del seguro de vida al que vamos a referirnos con sus siglas anglosajonas: IPID (Insurance Product Information Document).

También como consecuencia de la permanencia de las obligaciones de información en este texto, hay que señalar, tal y como recoge la exposición de motivos del Proyecto como su art. 1, y que la aplicación de la IDM I puso ya de manifiesto, la necesidad de garantizar el mismo nivel de protección a los clientes, cualquiera que sea el canal a través del cual se adquiera el producto de seguro, para que los destinatarios pudieran beneficiarse de normas comparables y así poder adoptar la decisión que consideren más adecuada para sus intereses. Precisamente, para poder comparar las características de los diversos canales de distribución, se consideran distribuidores de seguros no sólo a los mediadores, sino también a las entidades aseguradoras, incluidas por primera vez entre los distribuidores, y a otros participantes en el mercado que distribuyan productos de carácter auxiliar como son las agencias de viaje o las empresas de alquiler de automóviles, que serán considerados como mediadores de seguros complementarios salvo que reúnan las condiciones señaladas por el art. 51 PLDSRP para ser objeto de exención.

6 QUINTANS EIRÁS, R., “Información y conflicto de intereses...”, cit., p. 199. También, RES, n 175 , p. 379. 
Y se incluye también dentro del concepto de distribución a la actividad desarrollada a través de comparadores de seguros, siempre que en este último caso se permita al cliente celebrar directa o indirectamente un contrato de seguro al final del proceso, aunque es cierto que la atención que le ha prestado el legislador es ciertamente muy escasa, puesto que aparte de la mención que realiza en el art. 3 en relación al ámbito objetivo de aplicación no se encuentran en el texto más referencias, cuando tal vez hubiera sido oportuno en el ámbito que a nosotros nos interesa, que se hubiesen incorporado exigencias específicas de información al cliente ${ }^{7}$. En todo caso, la igualdad de trato entre los operadores y la protección del cliente requieren que las obligaciones pertinentes se extiendan a todas esas personas y entidades, y por ello especial hincapié se ha hecho en relación a la obligación de información previa regulando este aspecto en preceptos separados a diferencia del régimen conjunto que aparece en IDM II.

Además de la ampliación expresa que se ha producido en los sujetos obligados a proporcionar información, es importante destacar las diferencias que existen en la forma de ofrecerla, ya que se establecen deberes de distinto signo para los distribuidores en función de su obligación de conocer y evaluar a los clientes, con la circunstancia de que han de ser siempre coherentes con sus exigencias y necesidades, presentándole el producto de un modo comprensible para que pueda tomar la decisión más correcta conforme a sus intereses. Se diferencia así, como se verá más adelante, entre venta informada y venta asesorada. En el primer caso, el distribuidor ha de facilitar al cliente información objetiva acerca del producto de seguros de manera comprensible para que pueda tomar una decisión fundamentada. En la venta asesorada debe el distribuidor facilitar al cliente una recomendación objetiva y personalizada realizando un asesoramiento basado en un análisis objetivo que deberá prestar sobre la base del análisis de un número suficiente de contratos de seguro ofrecidos en el mercado y explicando además por qué un determinado producto va a satisfacer de forma más idónea sus exigencias y necesidades.

7 QUINTÁNS EIRÁS, Ma R., "Información y conflicto de intereses..., cit., p. 206. Igualmente, AA VV, "Insurtech, retos y desafíos de cara a la nueva distribución y contratación de seguros", RES, n 169, 2017, pp. 35 y 36. Parece lógico pensar que en estos entornos digitales la información se va a presentar de un modo insuficiente e inadecuado y, en principio, no se han previsto cautelas al respecto, cuestión que se plantea de manera concreta en relación a los robo-advisors. 
Al mismo tiempo, otro aspecto importante y problemático a tener en cuenta, puesto que en relación con él van a aparecer el mayor número de conflictos de interés, es la obligación del distribuidor de seguros de proporcionar al cliente, antes de la celebración del contrato de seguro, información sobre la naturaleza de la remuneración recibida en relación con el contrato de seguro. Esta obligación se completa, como veremos, para el caso de los mediadores de seguros, con la obligación de informar si en relación con el contrato trabajan a cambio de un honorario, de una comisión, de cualquier otro tipo de remuneración, incluida cualquier posible ventaja económica ofrecida u otorgada en relación con el contrato de seguro, o sobre la base de una combinación de cualquiera de los tipos de remuneración.

\section{OBLIGACIONES GENERALES DE INFORMACIÓN DE LOS DISTRIBUIDORES DE SEGUROS}

\subsection{Contenido de la obligación de información}

Hay una idea clave sobre la que reposa toda esta materia consistente en la necesidad de actuar siempre en beneficio del cliente asegurado, si bien es cierto que esta premisa admitiría matizaciones en función del tipo de distribuidor de que se trate, ya que no se puede pedir a todos ellos la misma defensa del interés de un consumidor. En todo caso, dicho de otro modo, existe un principio general de buena conducta de los distribuidores de seguros, íntimamente relacionado con la obligación de información a suministrar que va a depender, en principio, de la tipología de distribuidor, pero también de su naturaleza y de la fuente de la remuneración a percibir. Y habrá que valorar igualmente el concepto de asesoramiento. En este sentido, el art. 46 del PLDSRP acoge los que pueden considerar como los tres principios generales que deben regir la actividad de todos los distribuidores de seguro.

\subsubsection{E1 principio general}

En primer lugar, hay que destacar un principio general de buena conducta, tal y como hemos señalado, que implica que los distribuidores deben 
actuar siempre con honestidad, equidad y profesionalidad en beneficio de los intereses de sus clientes. La trascendencia de esta declaración programática es innegable, pero el legislador no se queda -no debe quedarse- en ella, sino que para hacerla efectiva establece en los artículos siguientes el conjunto de datos que los distribuidores han de transmitir a sus clientes, poniendo de manifiesto el deber de lealtad intrínseco a la relación que se genera entre el distribuidor y sus clientes. $\underline{8}$

Este principio general se completa con otros dos señalados en segundo y tercer lugar que vienen, en realidad, a derivarse del primero, ya que como se verá la forma de actuar de los distribuidores ha de ser siempre transparente imponiéndoles las obligaciones relativas a las comunicaciones publicitarias con un carácter positivo; por el contrario, las obligaciones relativas a la remuneración tienen un carácter negativo o de omisión, estableciendo en particular que un distribuidor de seguros no establecerá ningún sistema de remuneración, de objetivos de ventas o de otra índole que pueda constituir un incentivo para que este o sus empleados recomienden un determinado producto a un cliente si el distribuidor de seguros puede ofrecer un producto diferente que se ajuste mejor a las necesidades del cliente. En todo caso, se entiende que la transparencia en la revelación de la información relevante por parte de los distribuidores sobre la remuneración percibida y los servicios prestados puede mitigar los conflictos de interés. Se considera, sin embargo, que, si bien los principios señalados son aplicables a todos los distribuidores de seguros, su encaje resulta más creíble en relación a los corredores de seguros que son los que deben ofrecer un producto que se ajuste a las necesidades del cliente, más que a los agentes u operadores de banca-seguros, puesto que al contenido de la información a proporcionar por el agente de una compañía no se le presume la misma naturaleza que la que ha de proporcionar un corredor. ${ }^{?}$

\subsubsection{Publicidad}

En segundo lugar, como se ha señalado, y en este mismo orden se recoge en el art. 46, hay que tener en cuenta que la información que proporcio8 GIRGADO PERANDONES, P., “Transparencia y deberes de información en la actividad profesional del mediador de seguros. A propósito de la nueva Directiva de Distribución de Seguros", La Ley Mercantil, no 21, enero 2016, p. 8.

9 QUNTÁNS EIRAS, Mª R., RES, nº 175, p. 387. 
nen los distribuidores a sus clientes o posibles clientes debe ser además de precisa y clara, no engañosa, y las comunicaciones publicitarias serán claramente identificables como tales, sin poder, por tanto, inducir a confusión sobre su consideración. Aunque el texto de la norma puede sugerir que estamos ante cuestiones sobreentendidas, no cabe ninguna duda de que el énfasis puesto por el legislador resalta su importancia y la exigencia de su cumplimiento. Se trata, por tanto, de cuestiones que han de valorarse en consonancia con lo dispuesto por la normativa sobre publicidad y competencia desleal

\subsubsection{Remuneración y conflictos de interés}

En tercer lugar, como consecuencia de la vinculación existente entre los posibles conflictos de interés y las políticas de retribución de los distribuidores de seguros, y con la finalidad de evitar que tenga lugar dicha confrontación, se establecen exigencias ${ }^{10}$ dirigidas a impedir que los distribuidores puedan ser remunerados o remunerar a sus empleados de un modo que afecte a las obligaciones establecidas para velar por los intereses de los clientes.

Por ello, los distribuidores no podrán ser remunerados ni podrán evaluar el rendimiento de sus empleados a través de un sistema de remuneración, de objetivos de ventas o de otra clase, de modo que entre en conflicto con su obligación de actuar en el mejor interés de sus clientes, esto es, no podrán incentivar o recomendar la contratación de un seguro diverso de aquel que se adapte de mejor forma a las necesidades del cliente. Así pues, se les prohíbe recomendar un producto que les procure un mayor incentivo en su retribución, pero en detrimento de aquel que más satisfactoriamente se va a adaptar a lo requerido por el cliente, aunque le suponga una menor remuneración. Esta situación, aunque se aplica a todos los distribuidores de seguros, se pone particularmente de manifiesto en relación con los corredores ${ }^{11}$ que, como cuestión clave que es, puede comprometer la objetividad que les caracteriza.

10 El considerando 39 de la IDM II señala de forma muy oportuna que "[L]a continua ampliación de la gama de actividades que muchos intermediarios y empresas de seguros desarrollan simultáneamente ha incrementado las posibilidades de que surjan conflictos de intereses entre esas diferentes actividades y los intereses de sus clientes. Por ello, resulta necesario establecer normas que garanticen que tales conflictos de intereses no lesionen los intereses del cliente." 11 GASCO ORTÍZ, A., "Obligaciones de información y normas de conducta en el borrador de Anteproyecto de la Ley de distribución de seguros y reaseguros privados", La Ley Mercantil, no 46, abril 2018, p. 3. 
En definitiva, evitar los conflictos de interés se convierte en una cuestión clave dentro del mercado de la distribución de seguros y ofrecer información sobre la remuneración de los distribuidores es uno de los modos fundamentales para evitar tales situaciones de confrontación y conseguir mayor transparencia en el sector asegurador. ${ }^{12}$ Por este motivo, los sistemas de retribución y transparencia en torno a ellos ha sido tradicionalmente uno de los caballos de batalla de la distribución de seguros. $\frac{13}{3}$

\subsection{Sujetos obligados}

El PLDSRP contempla entre sus principales novedades la diferencia entre distribuidores y mediadores de seguros. Dentro del primer concepto incluye a los propios mediadores, a las entidades aseguradoras y también a los comparadores de seguros. A su vez, en la figura del mediador ha de contemplarse también al mediador de seguros complementario. Debe tenerse en cuenta también que la obligación de información afecta a todos los distribuidores de la Unión Europea que ejerzan en España en régimen de derecho de establecimiento o de libre prestación de servicios, quienes deberán informar a su clientela en los mismos términos que se establecen para los nacionales, mientras que cuando estos ejerciten estas mismas libertades comunitarias, deberán cumplir con las exigencias establecidas en los arts. 43 a 45 del PLDSRP.

\subsubsection{Mediadores de seguros}

El nuevo texto sigue basándose en las dos clases de mediadores ya conocidas como son los agentes de seguros, exclusivos o vinculados, u operadores de banca-seguros, también de ambas categorías, como mediadores dependientes de las entidades aseguradoras y los corredores de seguros y reaseguros, mediadores independientes que ofrecen a sus clientes asesoramiento basado en un análisis objetivo y personalizado, aunque la práctica ha venido poniendo de manifiesto que esta nítida separación no es tal.

12 Vid., QUINTÁNS EIRAS, Ma R., Revista General de Derecho Europeo, nº 39, 2016, pp. 15 y 16 .

13 QUINTÁNS EIRAS, Ma R., "Información y conflicto de intereses..., cit., p. 224. Y consecuencia de ello son también los cambios que se han ido produciendo en la elaboración de IDM II sobre esta cuestión hasta su aprobación definitiva, en los que ha tenido lugar una relajación de las exigencias inicialmente previstas en los borradores en cuanto a la información que sobre la remuneración de los distribuidores debía recibir el cliente asegurado. 
Como novedad, el PLDSRP crea y define en su art. 2.2 la figura del mediador de seguros complementario entendiendo por tal todo mediador de seguros, persona física o jurídica, distinta de una entidad de crédito o de una empresa de inversión ${ }^{14}$ que, a cambio de una remuneración, realice una actividad de distribución de seguros con carácter complementario, siempre y cuando la actividad profesional principal de dicha persona física o jurídica sea distinta de la de distribución de seguros; sólo distribuya determinados productos de seguro que sean complementarios de un bien o servicio; y los productos de seguro en cuestión no ofrezcan cobertura de seguro de vida o de responsabilidad civil, excepto cuando tenga carácter complementario al bien o servicio suministrado. En todo caso, solo podrán ser considerados mediadores cuando no estén excluidos del ámbito de aplicación del Proyecto de Ley y se inscriban en el correspondiente registro con esta condición de complementarios en alguna de las categorías de mediadores que se establecen. Se trata, por tanto, de otros participantes en el mercado que distribuyan productos de seguros con carácter auxiliar, como pueden ser las agencias de viajes o las empresas de alquiler de automóviles.

\subsubsection{Entidades aseguradoras}

La incorporación de las entidades aseguradoras a la lista de distribuidores de seguros contemplada en el art. 8 del PLDSRP se hace con el objetivo de garantizar el mismo nivel de protección a todos los clientes, cualquiera que sea el canal a través del cual celebran la contratación de un seguro. Se incluye, por tanto, la llamada venta directa dando lugar a una ampliación de los destinatarios del deber de información al asegurado que se ha justificado por la posible desprotección que sufriría el consumidor en el supuesto de que este canal de distribución no estuviese contemplado en la norma ${ }^{15}$ aunque lo cierto es que lo hace de un modo diferente, simplificando la información que ha de ser proporcionada por las compañías cuando ofrecen directamente el producto de seguro, tal y como se contempla en el art. 48 del PLDSRP.

\footnotetext{
14 Según vienen definidas en los apartados 1 y 2, del artículo 4.1 del Reglamento (UE) n. ${ }^{\circ}$ 575/2013 del Parlamento Europeo y del Consejo, de 26 de junio de 2013, sobre los requisitos prudenciales de las entidades de crédito y las empresas de inversión.

15 DÍAZ LLAVONA, C., "Propuesta de revisión de la Directiva 2002/92/CE de mediación de seguros. Antecedentes, principales novedades y aspectos discutibles, RES, no 150-151, 2012, pp. 255 y 256. También, SÁNCHEZ SANTIAGO, J. y CID BLASCO, T., Papeles de la Fundación, Fundación de Estudios Financieros, nº 48, 2013, pp. 118 y 121.
} 
En este contexto, como no podía ser de otro modo, se entiende por entidad aseguradora, tal y como dispone el art. 2.4, toda entidad acorde con la definición del art. 6.1 de la LOSSEAR.

Se establece también que los empleados que formen parte de las plantillas de las entidades aseguradoras podrán promover la contratación de seguros a favor de la entidad de la que dependan, considerándose que dichos seguros son distribuidos directamente por la entidad aseguradora para lo cual se pretende crear un registro interno sometido al control de la DGSFP en el que constarán inscritos los empleados que participen directamente en actividades de distribución, así como la persona responsable de la actividad de distribución o las personas que forman parte del órgano de dirección responsable de la actividad de distribución estableciéndose para ellas la obligación de estar inscritas en el registro administrativo especial de mediadores de seguros, de corredores de reaseguros, y de altos cargos de los distribuidores de seguros y reaseguros.

Esta incorporación ha suscitado opiniones dispares y se cuestiona el caos sistemático que puede provocar en la práctica, así como la falta de aplicación de algunas normas previstas ${ }^{16}$. Además, con la legislación actual en la mano las entidades aseguradoras tienen prohibido según establece el art. 5.c) de la LOSSEAR desarrollar actividades de mediación de seguros definidas en su normativa específica ${ }^{17}$, y la disposición adicional segunda del PLDSRP por la que se modifica esta norma no contempla ningún cambio en el precepto citado, que consideramos debería haberse realizado.

Y ello porque la distribución de seguros por entidades aseguradoras no puede considerarse como una fase independiente y perfectamente extrapolable del proceso de oferta y formación del contrato de seguro a celebrar, sino que es parte del mismo proceso y no una actividad diferente que requiera de un tratamiento separado. Se insiste, por ello, en que el lugar apropiado para su regulación, como se ha hecho en distintos

16 Muy crítico, en particular, es MUÑOZ PAREDES, J. Ma, RES, pp. 371 y 372. En su opinión, "[E]l error estriba en no darse cuenta de que la distribución por las aseguradoras (como cualquier otro contrato, del tipo que sea) no es más que una parte del proceso de oferta y formación del propio contrato de seguro, y no una actividad distinta que merezca un trato separado." 17 DÍAZ LLAVONA, C., Diario la Ley, 2017, pp. 3 y 4, sobre la problemática de incluir la labor desarrollada por las entidades aseguradoras y mediadoras en el mismo texto. 
ordenamientos como el alemán, el francés o el italiano, es la Ley de contrato de seguro como sede de los derechos de información del tomador en todo contrato. $\underline{18}$

Frente a esta situación, el PLDSRP establece en su art. 13 los requisitos que han de cumplir tanto los empleados que participen directamente en actividades de distribución, la persona responsable de la actividad de distribución o las personas que formen parte del órgano de dirección responsable de esta actividad, quienes, en definitiva, son lo que han de cumplir con las obligaciones de información al tomador del seguro. Todos ellos han de cumplir con el requisito de la honorabilidad comercial y profesional tal y como aparece definido en el art. 2 del PLDSRP. Igualmente, deberán las entidades garantizar, aunque en este caso el requisito solo se exige a la mitad de las personas que formen parte del órgano de dirección responsable de la actividad, que poseen los conocimientos y aptitudes apropiados mediante la superación de cursos de formación tal y como se prevé en el Proyecto y en las normas de desarrollo. Las entidades deberán proporcionar los medios necesarios para garantizar una formación continua adaptada a los productos distribuidos. Será la DGSFP, tal y como establece el art. 39 PLDSRP, la que establezca mediante resolución las líneas generales de los programas de formación que han de seguir estos colectivos y la que controle el registro actualizado que deberán llevar las entidades aseguradoras.

\subsubsection{Comparadores de seguros}

El ámbito funcional de actuación del PLDSRP se ha visto sensiblemente ampliado y así lo pone de manifiesto su art. 3.1 al entenderse también incluida dentro de la actividad de distribución la aportación de información relativa a uno o varios contratos de seguro de acuerdo con los criterios elegidos por los clientes a través de un sitio web o de otros medios, y la elaboración de una clasificación de productos, incluidos precios y comparaciones entre ellos, o un descuento sobre el precio de un contrato de seguro, cuando el cliente pueda celebrarlo directa o indirectamente utilizando un sitio web u otros medios. Por ello, especial mención realiza el Proyecto en su art. 8.3 a los mediadores de seguros que utilicen sitios web u otras técnicas de comunicación a distancia.

18 MUÑOZ PAREDES, J. Ma, RES, nº 171-172, 2017, pp. 371 y 372. También, DÍAZ LLAVONA, C., Diario la Ley, 2017, p. 4. 
En tal caso, se les van a exigir unas especiales obligaciones entre las que destaca la elaboración de políticas escritas que garanticen su transparencia y que deberán estar a disposición de la DGSFP. Se exige que tales políticas han de incluir, como mínimo, los criterios para la selección y comparación de los productos de las entidades aseguradoras; las entidades aseguradoras de las que ofrecen productos y la relación contractual con el distribuidor; si la relación con las entidades aseguradoras en cuestión es remunerada, en cuyo caso han de indicar la naturaleza de la remuneración; si el precio del seguro que figura al final de proceso está o no garantizado y la frecuencia con que la información de los distribuidores de seguros es actualizada. Se exige, igualmente, indicar la titularidad de estos sitios web, así como su condición, para que los usuarios puedan ejercer con las máximas garantías posibles los derechos de asistencia y defensa de sus intereses. El art. 9.5 a su vez establece que los mediadores, tanto agentes como corredores, podrán servirse de sitios web u otras técnicas de comunicación a distancia mediante las que se proporcione información al cliente comparando precios o coberturas de un número determinado de productos de distintas entidades.

Hay que tener en cuenta a este respecto, la exclusión expresa del ámbito del PLDSRP de los sitios web que, gestionados por autoridades públicas o asociaciones de consumidores, no tengan por objeto la celebración de contratos de seguro limitándose a comparar los productos de seguros disponibles en el mercado (art. 3.4 PLDSRP).

\subsection{Modalidades de transmisión de la información}

Las modalidades de transmisión de la información no varían sustancialmente con la nueva Ley y siguen el precedente ofrecido por el art. 43 de la LMSRP, aunque es cierto que se insiste en la posibilidad de utilizar páginas web y se disponen los requisitos que estas deben cumplir para poder ser consideradas como vehículos de la información a suministrar. Según establece el art. 56 PLDSRP, esta información deberá proporcionarse cumpliendo determinados requisitos de carácter general: en papel; de forma clara y precisa, comprensible para el cliente; en una lengua oficial del Estado miembro en el que se sitúe el riesgo o del Estado miembro del compromiso o en cualquier otra lengua acordada por las partes y de forma gratuita. 
En definitiva, lo que se pretende es que se traslade convenientemente la información al cliente, libre de cargas, en principio en papel, aunque si tenemos en cuenta lo dispuesto por el art. 56.3.b), que dispone que el cliente haya podido optar entre recibir información en papel o en otro soporte duradero y haya elegido este último soporte, nos permite afirmar que la información ha de proporcionarse en la modalidad elegida por aquel. Ninguna referencia se realiza ya en la norma proyectada, y debemos entender que esta posibilidad queda excluida, a la posibilidad prevista por el art. 43.2 de la LMSPR para que la información se facilite oralmente cuando el cliente lo desease y así lo solicitara en aquellos casos en los que resultase necesaria una cobertura de forma inmediata. En tales supuestos la información por escrito debía proporcionarse inmediatamente después de celebrarse el contrato y ajustarse de forma íntegra a los datos facilitados verbalmente por el mediador, generando en caso contrario la correspondiente responsabilidad del intermediario.

La información, en definitiva, podrá proporcionarse en papel, en un soporte duradero o a través de una página web. Por lo que respecta al soporte duradero, se permite transmitir con él la información cuando se den determinadas circunstancias que se señalan en el art. 56.4, a saber, que el uso del soporte duradero resulte adecuado en el contexto de las operaciones que tengan lugar entre el distribuidor de seguros y el cliente, y que el cliente haya podido optar entre recibir información en papel o en otro soporte duradero, y haya elegido este último soporte. La noción legal de soporte duradero (art. 2.18) como todo instrumento que permita a un cliente almacenar la información dirigida a él personalmente, de modo que pueda acceder a ella posteriormente para consulta, durante un período de tiempo adecuado para los fines a los que la información esté destinada y, lo que es más importante, que permita la reproducción sin cambios de la información almacenada, destaca la capacidad de conservación y almacenamiento de la información permitiendo al cliente acceder a la información o reproducirla garantizándole su inalterabilidad.

La información también puede proporcionarse a través de una página web, pero tanto en este caso como cuando se utilice un soporte duradero se proporcionará al cliente una copia en papel cuando este así lo solicite, y de forma gratuita, por lo que no parece que se esté se propugnando por el legislador la desaparición del papel como vehículo transmisor de la información a proporcionar. 
Esta transmisión podrá tener lugar también a través de un sitio web cuando vaya dirigida personalmente al cliente o concurran las siguientes circunstancias: a) Que facilitar esa información a través de un sitio web resulte adecuado en el contexto de las operaciones que tengan lugar entre el distribuidor de seguros y el cliente. b) Que el cliente haya aceptado que esa información se facilite a través de un sitio web. c) Que se haya notificado al cliente electrónicamente la dirección del sitio web y el lugar del sitio web en el que puede consultarse esa información. d) Que se garantice que esa información seguirá figurando en el sitio web durante el tiempo que razonablemente necesite el cliente para consultarla.

Por tanto, ha de probarse que el cliente tiene un acceso regular a internet y la comunicación entre el distribuidor y el cliente se llevará a cabo a través de una dirección de correo electrónico que se considerará válida a efectos de prueba. No se incluyen sitios web que gestionados por autoridades públicas o asociaciones de consumidores no tengan por objeto la celebración de contrato alguno, sino que se limiten a comparar los productos de seguro disponibles en el mercado.

En caso de venta por teléfono también han de diferenciarse el momento precontractual y el inmediatamente posterior a la celebración del contrato. De este modo, la información facilitada al cliente por el distribuidor de seguros antes de celebrarse el contrato, incluido el documento de información previa se comunicará conforme a las normas aplicables a la comercialización a distancia de servicios financieros a los usuarios de seguros, la Ley 22/2007, de 11 de julio. En tales casos, incluso cuando el cliente haya decidido recibir información previamente en un soporte duradero distinto del papel porque se dan las circunstancias dispuestas para ello, el distribuidor de seguros facilitará además al cliente la información que proceda inmediatamente después de celebrarse el contrato de seguro.

El PLDSRP dispone también en su disposición adicional tercera la obligación de los distribuidores de conservar la documentación precontractual independientemente del soporte en el que se ha entregado al cliente, tecnológico o papel, para poder acreditar, si es preciso, el cumplimiento de las obligaciones legales. Esta obligación se dispone por un plazo mínimo de seis años desde el momento de la finalización 
de los efectos del contrato. La enmienda núm. 48 sobre esta disposición, del grupo parlamentario Ciudadanos, pretende que la copia que deba ser conservada sea únicamente de naturaleza digital.

\section{INFORMACIÓN GENERAL PREVIA A ROPORCIONAR POR EL MEDIADOR DE SEGUROS. ESPECIAL REFERENCIA A LA CONDICIÓN DEL MEDIADOR Y A LA REMUNERACIÓN}

LEl PLDSRP regula en dos preceptos separados la información que han de presentar los mediadores de seguros y, como novedad, las entidades aseguradoras. De este modo, la información que tiene que proporcionar el mediador de seguros antes de la celebración del contrato de seguro se estipula en términos semejantes a los que se contemplaban por el art. 42 de la LMSRP, debiéndose informar sobre un conjunto de datos antes de la celebración del contrato de seguro, junto con la obligación de informar de posibles modificaciones si a lo largo de su duración la información inicialmente proporcionada sufriera cambios. El art. 47 del PLDSRP ha ampliado la información requerida haciendo un especial hincapié en los datos que se han de proporcionar sobre la condición en la que actúa el mediador y, sobre todo, en relación a la retribución a recibir. También recoge este art. 47 una referencia temporal al exigir que los datos se proporcionen con la suficiente antelación. Se trata este de un concepto que si bien es cierto no se encuentra definido ni en IDM II ni en el PLDSRP, sí aparece recogido en otras normas con carácter expreso, como sucede con MiFID II y el Reglamento PRIPs. $\underline{19}$

19 AA VV, RES, no 169, 2017, pp. 81 y 82. En concreto, el Considerando 83 de MiFID II dispone: "A la hora de determinar qué se entiende por suministrar información con suficiente antelación respecto de un momento contemplado en la presente Directiva, la empresa de servicios de inversión debe tener en cuenta, a la luz de la urgencia de la situación, el tiempo que necesita el cliente para leer y comprender la información antes de tomar una decisión de inversión. Es probable que el cliente necesite más tiempo para examinar información sobre un producto o servicio complejo o con el que no esté familiarizado o un producto o servicio con el que no tenga experiencia, que para reflexionar sobre un producto más sencillo o más familiar o con el que el cliente haya tenido ya experiencia."

También se refiere a esta cuestión el Considerando 26 del Reglamento PRIPS: "A fin de que el inversor minorista pueda tomar una decisión de inversión informada, debe exigirse a las personas que asesoran sobre productos empaquetados o basados en seguros o que los venden 
En consecuencia, con anterioridad a la celebración del contrato de seguro en el que participe acercando posturas, el mediador deberá proporcionar al cliente con suficiente antelación, un conjunto de datos ciertamente amplio que pasamos a reseñar, situándose en primer lugar la propia identificación del mediador y su condición como tal, además de su dirección, pues resulta fundamental para el tomador del seguro conocer el tipo de mediador con el que va a mantener una relación, al objeto de valorar la selección que ha realizado y, en consecuencia, el tipo de información que le tiene que proporcionar. Estas circunstancias están muy relacionadas con la necesidad de informar sobre si se ofrece o no algún tipo de asesoramiento sobre el objeto de la mediación y tal y como se encuentra definido en el art. 2.15 del Proyecto, como "recomendación personalizada hecha a un cliente, a petición de éste o a iniciativa del distribuidor de seguros, respecto de uno o más contratos de seguro", sin que la norma establezca en principio diferencias definidas en función del tipo de intermediario de que se trate. En este sentido, no cabe duda que concretar el tipo de asesoramiento que deben prestar los distintos tipos de intermediarios de seguros y, por ende, el tipo de venta que se realiza, es un dato necesario para lograr una mayor transparencia, ya que podemos encontrarnos ante situaciones muy diversas. .0 Se trata, por tanto, de una cuestión de fundamental importancia si se tiene en cuenta que la calidad del asesoramiento que realiza es uno de los principales rasgos distintivos de los corredores de seguros como intermediarios independientes.

La información también ha de versar sobre los procedimientos existentes para la formulación de quejas sobre la actuación del mediador y los relativos a la resolución extrajudicial de conflictos entre las partes. Se ha de indicar también el registro en el que el mediador se encuentre inscrito y el modo en que se puede realizar la comprobación de la inscripción con el objetivo de garantizar la categoría profesional del sujeto que vende el seguro. Y, por supuesto, información relativa al tratamiento de los datos personales del cliente de conformidad con lo establecido en el artículo

que faciliten el documento de datos fundamentales con la suficiente antelación antes de que se realice cualquier operación. Este requisito debe aplicarse con independencia de dónde y de qué modo tenga lugar la operación. No obstante, si la operación se realiza utilizando medios de comunicación a distancia, el documento de datos fundamentales puede entregarse inmediatamente después de la realización de la operación, a condición de que no sea posible facilitar dicho documento por adelantado y de que el inversor minorista dé su consentimiento..."

20 Vid., QUINTÁNS EIRAS, Mª R., Revista General de Derecho Europeo, nº 39, 2016, p. 13. 
5.1 de la Ley Orgánica 15/1999, de 13 de diciembre, de Protección de Datos de Carácter Personal, que deberá ser sustituida por la nueva Ley Orgánica 3/2018, de 5 de diciembre, de Protección de Datos Personales y garantía de los derechos digitales, en concreto, por lo establecido por su art. 11.

Parte de la información que se ha de suministrar con carácter previo está directamente relacionada con la entidad aseguradora y la posible relación existente con el intermediario con el objeto de evitar posibles conflictos de interés y no lesionar los de los clientes; en concreto, el texto se refiere a la posibilidad de que el mediador posea una participación directa o indirecta del 10 por ciento o superior de los derechos de voto o del capital en una entidad aseguradora determinada, o si una entidad aseguradora determinada o una empresa matriz de dicha entidad posea una participación directa o indirecta del 10 por ciento o superior de los derechos de voto o del capital del mediador de seguros.

En este ámbito se exige también determinar cómo actúa el intermediario, lo cual no es ni mucho menos una cuestión intrascendente y superflua, sino todo lo contrario, por la enorme confusión en la que se mueven los clientes tal y como la práctica se ha ocupado de poner de manifiesto. Ha de comunicarse, por tanto, si lo hace en representación del cliente o, por el contrario, actúa en nombre y por cuenta de la entidad aseguradora, para conocer de este modo el grado de vinculación del mediador con la entidad, respecto a la que se realizan las precisiones pertinentes en relación al tipo de intermediario de que se trate.

De fundamental importancia es también la exigencia reflejada en el art. 47.1.i) según la cual, y en relación al contrato ofrecido o sobre el que se ha asesorado, se ha de detallar si se facilita dicho asesoramiento basándose en un análisis objetivo y personalizado. El legislador parece estar refiriéndose en este caso a la venta asesorada de modo que estaríamos ante la figura del corredor de seguros, diferenciándose en su caso del agente de seguros vinculado, con la problemática que plantea esta diferenciación, que habrá de girar en torno a una situación de dependencia o no respecto a las entidades aseguradoras, lo que no deja de ser ambiguo, siendo este uno de los motivos por los que se reclama del legislador, no una simple transposición de la directiva, sino un reflejo de las circuns- 
tancias y situaciones existentes en el mercado español.

El precepto en cuestión, continúa señalando que, si el mediador está contractualmente obligado a realizar actividades de mediación de seguros exclusivamente con una entidad o, en su caso, autorizado con varias entidades, deberá informar de los nombres de dichas entidades aseguradoras. Por el contrario, si no está contractualmente obligado a realizar actividades de distribución de seguros con una o varias entidades aseguradoras y además no facilita asesoramiento basándose en un análisis objetivo y personal, en este caso deberá informar de los nombres de las entidades aseguradoras con las que pueda realizar, o de hecho realice, actividades de seguros en el producto de seguro ofertado - se supone que estamos ante un agente de seguros exclusivo sin que de nuevo el legislador sea la suficientemente claro sobre el qué tipo de mediador al que pretende referirse proporcionando esta concreta información.

En el caso de los operadores de banca-seguros, a los que sí se refiere expresamente, deberán, adicionalmente, comunicar a su clientela que el asesoramiento prestado se facilita con la finalidad de contratar un seguro y no cualquier otro producto que pudiera comercializar la entidad de crédito. Con esta exigencia lo que se pretende es lograr que el cliente sepa en todo momento cuál es el producto que efectivamente va a contratar. ${ }^{21}$

Como puede apreciarse, el legislador obliga a informar de la situación concreta en la que se encuentra el mediador y la forma en la que trabaja en el mercado, aunque, como ya se ha señalado y ahora se reitera, es cierto que debería haber adaptado de una forma más ajustada las exigencias de la directiva comunitaria a la concreta realidad del mercado de distribución de seguros español.

En esta lista de información a suministrar, especial consideración ha de otorgarse a la relativa a la naturaleza de la remuneración que se va a percibir en relación con el contrato de seguro, debiéndose proporcionar referencias sobre su naturaleza y también sobre la base de cálculo que se utiliza para su concreción. No se requiere informar, pues, como en algún momento se exigió en los trabajos de elaboración de la directiva y teniendo en cuenta las importantes críticas que esta obligación recibió 21 GASCO ORTíZ, A., La Ley Mercantil, nº 46, abril 2018, p. 3. 
durante el proceso de su elaboración ${ }^{22}$ sobre la cantidad exacta a percibir, ni mucho menos se prevé que la información sobre la remuneración deba hacerse de forma que pudiese realizarse una comparación entre los intermediarios y los aseguradores directos.

Esta cuestión que tantas fricciones causó entre la Comisión y los mediadores, finalmente ha salido adelante en el modo que señalamos y, a pesar de que las exigencias iniciales han quedado bastante desdibujadas, se considera un importante avance en la protección de los consumidores y en el aumento de la transparencia, poniendo de manifiesto que la información tiene un coste. Se mantiene, sin embargo, la práctica habitual consistente en que el cliente no recibe el desglose entre el precio de la prima y el precio pagado por servicio del mediador, por lo que continua sin conocer el coste concreto de tales servicios con carácter general.

En todo caso, está previsto que la incorporación de esta información permita a los clientes realizar la elección más adecuada para la cobertura de sus necesidades y también del tipo de mediador que mejor puede atender sus intereses, pues no debe dejarse a un lado que la remuneración es una de las cuestiones fundamentales, junto al asesoramiento, que caracterizan a la figura de los corredores de seguro. Se considera además que la inclusión de este concepto en el precio del seguro va a dar lugar a un importante incremento de la competencia en el sector de la distribución al garantizar la recepción de una información más amplia sobre los productos y los costes. Proporcionar información sobre la retribución también va a facilitar a los consumidores realizar una comparación de coberturas y precios del seguro en los distintos canales de distribución,

22 Vid., SIERRA NOGUERO, E., "La remuneración del mediador de seguros en la propuesta de nueva directiva de mediación de seguros", en QUINTÁNS EIRAS, Mª R., (Dir.), Estudios sobre Mediación de Seguros Privados, Thomson Reuters Aranzadi, Madrid, 2013, pp. 291 y ss, en particular, 324 y ss. Dichas críticas aparecen relacionadas con el exceso de requisitos exigidos a los mediadores y también con la posibilidad de complicar la percepción que el consumidor va a tener de lo que está pagando por la obtención del servicio. A ello deben añadirse los costes que la implantación de estos deberes de información va a suponer en la práctica. Vid., igualmente, QUINTÁNS EIRAS, Ma R., Revista General de Derecho Europeo, nº 39, 2016, en particular, pp. 18 y ss, quien aboga por un tratamiento diferenciado en función del tipo de intermediario que intervenga en la celebración del contrato. Sin embargo, añade, que en el caso de los agentes de seguros u operadores de banca-seguros, ya sea su actuación en exclusiva o vinculados, la remuneración la paga la compañía aseguradora, sin que exista inconveniente alguno para que este dato se traslade al cliente, pero sin creer que esta información aporte mayor protección a los asegurados. 
así como un conocimiento más completo de los servicios prestados por el intermediario y los costes correspondientes.

En particular, el art. 47 exige en torno a la naturaleza de la remuneración detallar si los mediadores trabajan a cambio de un honorario, esto es, cuando la remuneración es abonada directamente por el cliente, en cuyo caso estaremos ante un corredor, o si la actividad se realiza a cambio de una comisión de algún tipo en el supuesto de que la remuneración está incluida en la prima del seguro. En este caso, la información ha de ser especialmente clara para evitar cualquier distorsión de la competencia así como posibles conflictos de interés en el supuesto de que estemos ante el pago de un servicio de forma indirecta por parte del cliente, como un posible recargo en la prima que se destine a la comisión que recibe el corredor. $\underline{\underline{23}}$

También se ha informar cuando se trabaja a cambio de cualquier otro tipo de remuneración, incluida cualquier posible ventaja económica ofrecida u otorgada en relación con el contrato de seguro o sobre la base de una combinación de cualquiera de los tipos anteriores de remuneración. Eso sí, hay que tener en cuenta que, cuando el cliente acuerde por escrito con el mediador de seguros el abono de determinados honorarios, éste informará al cliente del importe de dicho honorario, en cuyo caso sí estaríamos ante un desglose concreto de los conceptos, o, cuando ello no sea posible, el método para calcularlo.

Además de esta información previa, durante la vigencia del contrato de seguro el mediador deberá proporcionar al cliente información sobre su remuneración en dos supuestos en concreto: por un lado, cuando no tenga lugar cambio alguno en el contrato de seguro, en tal caso, si con posterioridad a la celebración del contrato el cliente efectúa en virtud del mismo algún pago distinto de las primas periódicas y los pagos previstos, se le facilitará también información sobre cada uno de los pagos hechos. Por otro lado, si se produjese alguna modificación en el contrato de seguro, entonces el mediador deberá informar al cliente con ocasión de la modificación o prórroga del contrato si se han producido alteraciones en la información inicialmente suministrada, tanto en lo que se refiere a la remuneración del mediador, como a la modificación de cualquier otro 23 QUINTÁNS EIRAS, Ma R., Revista General de Derecho Europeo, nº 39, 2016, p. 20. 
dato exigido por este artículo.

\section{INFORMACIÓN GENERAL PREVIA PROPORCIONAR POR LA ENTIDAD ASEGURADORA}

En este precepto se establece la información que ha de proporcionar la entidad aseguradora cuando realice de forma directa labores de distribución de seguros, como novedad frente a la LMSRP, lo que va a suponer mayores obligaciones para las entidades que han de adaptarse a la nueva situación..$^{24}$ Se han de proporcionar, como es lógico, datos coincidentes con la exigencia de información previa a los mediadores, como su identidad y dirección, así como su condición de entidad aseguradora, aunque a las empresas de seguros y reaseguros no se les va a exigir registrarse además como intermediarios puesto que ya son objeto de la correspondiente inscripción conforme a las normas de supervisión. Sin embargo, como señala el art. 7.1 del PLDSRP, sí se deberá inscribir a la persona responsable de la actividad de distribución y, en su caso, a las personas que formen parte del órgano de dirección responsable de las actividades de distribución.

Igualmente, la norma exige informar en el caso de que la entidad aseguradora ofrezca asesoramiento en relación con los productos de seguro comercializados. Se trata este de un dato que puede generar cierta controversia puesto que si bien es cierto que concretar sobre esta cuestión cuando la comercialización del seguro se realiza por mediadores es lógico -y aun así, se plantean interrogantes en función del tipo de mediador de que se trate-, no resulta tanto cuando de lo que se trata es de una contratación directa, puesto que en tal caso este asesoramiento requiere de una cierta distancia respecto de las compañías y su consideración como algo propio de los profesionales del sector considerados independientes. En sentido estricto, solo en este último caso se puede llevarse a cabo una labor de asistencia y consejo que pueda calificarse como asesoramiento, con independencia de su amplitud ${ }^{25}$ y que en todo caso habrá que diferenciar, en particular, en materia de responsabilidad. Por ello, si todos los distribuidores van a poder asesorar, al menos, habrá que clasificar $24 \quad$ GASCO ORTÍZ, A., La Ley Mercantil, nº 46, abril 2018, p. 4.

25 DÍAZ LLAVONA, C., Diario la Ley, 2017, p. 11. QUINTÁNS EIRAS, $M^{a}$ R., "Información y conflicto de intereses..., cit., p. 218. 
los distintos tipos de asesoramiento posibles y las consecuencias de su incumplimiento, en el caso concreto, las que correspondan a las entidades aseguradoras y a sus empleados. $\underline{26}$

También hay que informar sobre los procedimientos existentes para la formulación de quejas sobre la actuación del mediador y los relativos a la resolución extrajudicial de conflictos entre las partes. En relación a la cuestión fundamental de la remuneración, la entidad aseguradora debe proporcionar al cliente antes de la celebración de un contrato de seguro, información sobre la naturaleza de la remuneración percibida por sus empleados en relación con el contrato de seguro con el objeto de evitar los posibles conflictos de interés que se pueden plantear, en particular, la exigencia a las entidades aseguradoras de comunicar la base de cálculo de la remuneración variable que corresponda a sus empleados por la venta del producto. Durante la vigencia del contrato, la entidad aseguradora también deberá informar al cliente que efectúe algún pago en virtud del contrato distinto de las primas periódicas y los pagos previstos y cuando se produzcan alteraciones en la información inicialmente suministrada con ocasión de la modificación o prórroga del contrato de seguro.

Además, hay que tener en cuenta que el deber de información previo regulado en los apartados anteriores también será exigible con ocasión de la modificación o prórroga del contrato de seguro si se han producido alteraciones en la información inicialmente suministrada

\section{INFORMACIÓN Y ASESORAMIENTO PREVIOS SOBRE EL CONTRATO DE SEGURO}

A diferencia de la LMSRP que solo contemplaba la comunicación de datos en relación con el alcance de la actividad desarrollada por el mediador, en el nuevo texto esta obligación de información se exige también acerca del propio contrato de seguro y, además, como veremos en el siguiente apartado, con un formato estandarizado. Por ello, también puede realizarse aquí la misma crítica hecha en relación a la inclusión de las entidades aseguradoras como

26 MUÑOZ PAREDES, J.M ${ }^{a}$, RES, n 171-172, p. 371, quien pone de manifiesto cómo la responsabilidad de los corredores es contractual, ya que forma parte del contrato que les vincula con sus clientes y a este ámbito se circunscribe la labor de asesoramiento que realizan, que sugiere enormes dificultades en el caso de la distribución directa. 
sujetos obligados por el PLDSRP a proporcionar determinada información en el sentido de que la ubicación correcta de este régimen debe ser la LCS, formando parte de la etapa precontractual, con independencia de que la relación contractual se celebre directamente o con la intermediación de un mediador. ${ }^{27}$

\subsection{Aspectos generales}

El PLDSRP exige a los distribuidores de seguros, tanto a los mediadores como a las entidades aseguradoras, basándose en la información obtenida del cliente y en las exigencias y necesidades de este último, proporcionar información objetiva acerca del producto de seguro de forma comprensible para que el cliente pueda tomar la decisión con conocimiento de los datos precisos, en función de la complejidad del producto y del propio tipo de cliente de que se trate.

En relación al asesoramiento se establece además que si este se facilita antes de la celebración de un contrato de seguro el distribuidor de seguros también facilitará al cliente una recomendación personalizada en la que se explique por qué un determinado producto, y no otro, es el que va a poder satisfacer mejor las exigencias y las necesidades del cliente. La citada obligación se extiende a todos los distribuidores de seguro sin limitarla, en principio, a los corredores en función de su obligación de realizar un análisis objetivo, como establece este precepto. Con el nuevo texto, y a diferencia de la limitación a los corredores que establecía la LMSRP, ahora los agentes, los operadores de banca-seguro y las entidades aseguradoras deberán explicar igualmente a los tomadores los motivos por los que un producto se ajusta más a sus necesidades, lo que conllevará las correspondientes responsabilidades.

27 DÍAZ LlAVONA, C., Diario La Ley, 2017, pp. 10 y 11. No debe olvidarse, en todo caso, que también el art. 96 de la LOSSEAR establece un deber general de información previa de las entidades aseguradoras a los tomadores de seguro. Vid., PEÑAS MOYANO, M. J., "Conductas de mercado", en AA VV, Un derecho del seguro más social y transparente, en BATALLER GRAU, J., PEÑAS MOYANO, M.J., (Dirs), Cívitas Thomson Reuters, Madrid, 2017, pp. 765 y ss. Aquí se pone de manifiesto una cuestión no resuelta por el PLDSRP como es el encaje de estas normas con el resto de disposiciones en materia de seguros derivada de la ampliación del ámbito subjetivo realizado por el Proyecto de Ley. No se ha tenido en cuenta que la relación entre las entidades aseguradoras y los tomadores está regulada también en la LOSSEAR, así como en su Reglamento de desarrollo, imponiendo aquel deber de información precontractual respecto a un conjunto de datos que deben ser proporcionados por el asegurador. Vid., QUINTÁNS EIRAS, Ma R., "Información y conflicto de intereses..." cit., p. 203. 
Esta generalización de la posibilidad de prestar asesoramiento no modifica su concepto que sigue tratándose de un análisis objetivo y personalizado sobre la base del análisis de un número suficiente de contratos de seguro ofrecidos en el mercado de modo que pueda formular una recomendación personal, ateniéndose a criterios profesionales, respecto al contrato de seguro que sería adecuado a las necesidades del cliente (art. 49.2)..$^{28}$ La cuestión que se plantea al respecto no es tanto la propia previsión de la posibilidad de asesorar por parte de todas las categorías de mediadores, lo cual en sí mismo resulta oportuno y aún más su tratamiento por el legislador, sino que desaparece la diferencia por este concepto entre las dos grandes categorías de mediadores, agentes y corredores, que existía hasta el momento, y que venía calificándose como uno de los grandes logros de la LMSRP, sin olvidar la diferente responsabilidad que caracteriza a los dos tipos de mediadores. ${ }^{29}$

\subsection{Tipos de venta: venta informada y venta asesorada}

Por tanto, y conforme establece el art. 49 del PLDSRP, el distribuidor siempre ha de analizar la situación del cliente y ofrecerle un determinado tipo de venta, que puede conllevar una labor de asesoramiento o solo proporcionar información, en ambos casos adaptada a las características del cliente.

Un primer tipo de venta puede calificarse como venta informada (art. 49.1 PLDSRP) o venta sin asesoramiento según el art. 20 de IDM II. $\frac{30}{3}$ Ha de entenderse como aquella en la que el distribuidor de seguros se limita a proporcionar información objetiva sobre un producto de seguro que el cliente ha solicitado previamente ${ }^{31}$ y se ha de realizar conforme a sus exigencias y necesidades, pero sin entrar en detalles personales del cliente contemplando únicamente necesidad genéricas, comunes a amplios colectivos de clientes. $\underline{32}$

28 MUÑOZ PAREDES, J. Ma, RES, no 171-172, p. 371.

29 MUÑOZ PAREDES, J. Ma a $^{\mathrm{a}}$ RES, nº 171-172, p. 371 y QUINTÁNS EIRAS, Mª R., RES, $\mathrm{n}^{\circ}$ 175, p. 393, muy crítica esta última autora con la transposición al PLDSRP de los tipos de venta contemplados en MiFID II y en IDM II.

30 Vid., al respecto, SOLÁ FERNÁNDEZ, F., El proceso precontractual en el contrato de seguro: nuevo marco jurídico, Cuadernos de la Fundación Mapfre, nº 220, 2017, p. 78.

31 AA VV, RES, no 169, 2017, p. 67 y GASCO ORTÍZ, A., La Ley Mercantil, n 46, abril 2018, p. 3.

32 SOLÁ FERNÁNDEZ, F., El proceso precontractual..., cit., p. 105. 
Para ello, el distribuidor se basará en los datos obtenidos del propio cliente persiguiendo proporcionarle información objetiva y comprensible del producto de seguros para que pueda tomar una decisión fundada, pero sin facilitarle asesoramiento. En tal supuesto, el distribuidor deberá realizar un análisis de adecuación para obtener información del cliente sobre sus conocimientos y experiencia en el ámbito de inversión propio de la clase de producto y de este modo poder determinar si es adecuado para ese cliente. Puede suceder también que el cliente no facilite información suficiente o fidedigna al distribuidor sobre sus conocimientos o experiencia, en cuyo caso tendrán que advertir que no está en condiciones de decidir si el producto es o no adecuado para su contratación.

La llamada venta asesorada o con asesoramiento (art. 49.2) ${ }^{\frac{33}{3}}$ se entiende como aquella que se basa en una recomendación personalizada hecha al cliente, atendiendo a sus rasgos y necesidades propias, a petición de este o a iniciativa del distribuidor de seguros, respecto de uno o más contratos de seguro. En definitiva, el distribuidor facilita asesoramiento al cliente (art. 2.15 PLDSRP) implicando un mayor conocimiento de sus necesidades y un mayor detalle en las informaciones solicitadas al cliente e, igualmente, en las que se han de proporcionar. En tales supuestos, corresponde al distribuidor realizar un análisis de idoneidad que puede tener diverso alcance en función del producto que se ofrezca o se pretende contratar, pero que en todo caso excede de la obligación general de informar que nos ocupa, y que no se extiende en ningún caso a los clientes profesionales, tal y como están recogidos en el art. 2.23 del PLDSRP, como aquellos a los que se refiere el art. 205 del TRLMV. Se pretende además fomentar que las ventas sean de este tipo. $\underline{\underline{34}}$

El tipo de venta que debe realizar el distribuidor dependerá de la complejidad de producto que se propone y, por supuesto como se ha visto ya, del tipo de cliente. En el apartado 4 de este art. 49, se contempla un supuesto relacionado con las ventas cruzadas, vinculadas o combinadas recogidas en el art. 58, en cuyo caso se obliga igualmente al distribuidor a suministrar al cliente la información pertinente sobre el producto de seguro de forma comprensible, de modo que el cliente pueda tomar una decisión fundada. Esta exigencia se extiende también a los mediadores de seguros

33 Vid., igualmente, art. 20 IDM II y SOLÁ FERNÁNDEZ, F., El proceso precontractual..., cit., p. 78.

34 QUINTÁNS EIRAS, Ma R., "Información y conflicto de intereses..., p. 216. 
del Espacio Económico Europeo que ejerzan en España en régimen de derecho de establecimiento o en régimen de libre prestación de servicios.

\section{DEBER GENERAL DE INFORMACIÓN PREVIA SOBRE EL CONTRATO DE SEGURO DISTINTO AL SEGURO DE VIDA: DOCUMENTO DE INFORMACIÓN PREVIA}

Otra de las principales novedades contempladas en el PLDSRP es la previsión de un documento normalizado en el que el legislador contempla que los distribuidores han de proporcionar una información estandarizada y que supone un importante avance en la consecución de la ansiada transparencia en el sector. $\frac{35}{}$ Dicho documento de información previa (IPID) está previsto en el art. 49 del texto, pero únicamente para cuando se distribuyan productos de seguro distintos al seguro de vida. Llama la atención que este requerimiento solo tenga lugar en relación a estos seguros distintos al de vida y de la distribución de productos de inversión basados en seguros, pero la idea en la que se basa el IPID es mejorar la manera en que se venden los productos de seguro para que aporten beneficios reales a los consumidores en la línea de los seguros de vida ahorro o productos de inversión basados en seguros y que no sean los únicos a los que se apliquen nuevas exigencias de información, teniendo en cuenta además que tradicionalmente se les venía exigiendo una información mucho más exhaustiva y en el caso concreto del IPID la exhaustividad no es el principio a utilizar. Las autoridades europeas se han propuesto que la venta de pólizas de hogar o autos, es decir, de los seguros generales, también gane en transparencia y por eso se va a implantar un folleto que reúna los datos clave que los clientes deben recibir en cualquier país de la Unión antes de la contratación, con independencia del tipo de venta que se lleve a cabo y, por tanto, si hay asesoramiento o no por parte del distribuidor. Se trata, en consecuencia, de un documento general, no personalizado. $\frac{36}{}$

35 SOLÁ FERNÁNDEZ, F., El proceso precontractual..., cit., p. 79.

36 SOLÁ FERNÁNDEZ, F., El proceso precontractual..., cit., p. 80. 
IDM II (art. 20. 6. 7 y 8) exige, pues, que los productores de productos de seguro distintos del seguro de vida enumerados en el anexo I de la Directiva 2009/138/CE del Parlamento Europeo y del Consejo (Solvencia II) elaboren un documento normalizado de información sobre el producto de seguro en el que se facilite a los clientes la información necesaria acerca de dichos productos, a fin de que el cliente pueda tomar una decisión con conocimiento de causa, cuyo contenido aparece reflejado en su art. 20.8. Permite además a los Estados miembros la posibilidad de exigir una información más estricta que la que aquí recogida. En todo caso, la norma que contempla dicho documento es el Reglamento de ejecución (UE) 2017/1469 de la Comisión, de 11 de agosto de 2017, por el que se establece un formato de presentación normalizado para el documento de información sobre productos de seguro, que ha sido adoptado como un reglamento de aplicación directa.

EIOPA a la hora de elaborar el prototipo se ha basado en varias pruebas con consumidores $\frac{37}{}$ y también en las consideraciones trasladadas por la industria aseguradora en las diferentes consultas abiertas con este propósito, además de la consulta a las respectivas autoridades nacionales, para elaborar el folleto que recoge el Reglamento2017/1469. Una cuestión fundamental es que la longitud máxima del IPID debe ser, al imprimirse, de dos páginas A4 o, si se demuestra necesario, hasta tres páginas del mismo tamaño.

La finalidad es proporcionar a los clientes información sobre el producto que sea fácil de leer, comprender y comparar, para lo cual debe utilizarse un diseño, una estructura y un formato comunes a la hora de presentar la información exigida. En particular se fomenta la utilización de iconos o símbolos. Además, se señala, la información sobre posibles adiciones o coberturas opcionales no debe ir precedida de marcas de verificación, cruces o signos de exclamación. La intención, pues, es que los datos aparezcan agrupados con concisión y sencillez, de modo que utilizado correctamente el documento puede contribuir de forma decisiva de mercado se desarrolló en dos fases diferenciadas pasándose de cinco a tres modelos de formatos sobre productos de seguros, en concreto, de automóviles, salud y hogar. Los resultados obtenidos permitieron comprobar que la presentación por columnas, las secciones diferenciadas y la utilización de iconos, símbolos y colores manifestaban las preferencias de los consumidores. 
a que los asegurados no se vean perjudicados por cláusulas negociales limitativas y sorprendentes. $\frac{38}{}$

Se pretende también que este documento informativo permita la comparación de diferentes seguros para que el cliente pueda tomar una decisión de compra informada, incluso sin contar con muchos conocimientos sobre este tipo de productos. En ningún caso, eso sí, el IPID reemplazará la documentación contractual que se proporciona con una póliza de seguro para garantizar con ello la exigencia de brevedad y también de independencia. $\frac{39}{}$ Por tanto, cualquier personalización del cliente se hará a través de los términos y condiciones de la póliza y no en el folleto.

La elaboración de tal documento compete a la empresa de seguros correspondiente o, como establece la exposición de motivos de IDM II, en aquellos Estados miembros en los que el intermediario de seguros diseñe el producto de seguro, a dicho intermediario. El intermediario de seguros debe explicar al cliente las características esenciales de los productos que vende y, por lo tanto, su personal debe disponer de los recursos y el tiempo necesarios para ello.

En consecuencia, antes de la celebración de un contrato de seguro, el tomador posible debería recibir dos notas informativas: una de ellas ha de incluir información sobre el mediador de seguros o sobre la entidad aseguradora que realiza la actividad de distribución directamente; en la otra nota informativa que pasa a denominarse documento de información previa, se va a incluir la información correspondiente sobre el producto de seguro, de forma particular, las razones por las cuales dicho producto es el que mejor se ajusta a las necesidades del potencial tomador.

\subsection{Contenido del IPID}

La información concreta sobre el seguro ha de situarse inmediatamente debajo del nombre del productor y ha de contemplar la relativa al tipo de

38 MIRANDA SERRANO, L.Mª., "Transparencia en la contratación de seguros: condiciones generales y particulares", RES, nos. 171-172, 2017, p. 291 y pp. 300 y ss.

39 SOLÁ FERNÁNDEZ, F., El proceso precontractual..., cit., p. 80. 
seguro de que se trate. Ha de estar dispuesta en una serie de títulos que han de seguir el orden siguiente: así, en la parte superior del documento ha de aparecer, como se ha señalado, la información sobre el tipo seguro, que se incluirá en la sección que lleva por título "¿En qué consiste este tipo se seguro?" A continuación, se ofrecerá un resumen de la cobertura con inclusión de los principales rasgos asegurados, que debe aparecer en la sección "¿Qué se asegura?", de igual modo que los datos relativos a la suma asegurada. En estos supuestos, cada elemento informativo que figure en esta sección deberá ir precedido de una marca de verificación verde. A su vez, la información sobre el ámbito geográfico de aplicación, cuando proceda, se reflejará en la sección que lleva por título “¿Dónde estoy asegurado?" En este supuesto, cada elemento informativo que figure en esta sección deberá ir precedido de una marca de verificación azul.

El resumen de los riesgos excluidos se expresará en la sección que lleva por título “¿Qué no está asegurado?” y cada elemento informativo que figure en ella deberá ir precedido de una $\mathrm{X}$ en rojo; las principales exclusiones sobre las cuales no es posible presentar solicitudes de reclamación deberán incluirse en la sección con el título “¿Existen restricciones en lo que respecta a la cobertura?" y cada elemento informativo que figure en esta sección deberá ir precedido de un signo de exclamación en naranja; la información sobre las obligaciones pertinentes contraídas al inicio y durante la vigencia del contrato quedarán incluidas en la sección con el título “¿Cuáles son mis obligaciones?” y las relativas a las condiciones de pago de las primas y su duración en la sección “¿Cuándo y cómo tengo que efectuar los pagos; la información sobre la duración del contrato incluyendo la fecha de inicio y la de finalización en la sección “¿Cuándo comienza y finaliza la cobertura?” Por último, sobre modalidades de rescisión del contrato, la información se reflejará en la sección que lleva por título "¿Cómo puedo rescindir el contrato?" Se permite en caso de que resulte necesaria la utilización de subtítulos.

\subsection{Presentación e iconos}

Cada sección deberá estar encabezada por iconos que representan visualmente el contenido del título, tal y como se puede comprobar en el documento que adjuntamos. Eso le hace particularmente llamativo, 
también por los colores utilizados, al representar visualmente el contenido, lo que llamará la atención del cliente haciendo que su capacidad para retener la información sea mayor ${ }^{40}$. Por tanto, la información sobre los principales riesgos asegurados irá encabezada por el icono de un paraguas, que será de color blanco sobre fondo verde o verde sobre fondo blanco. La información sobre el ámbito geográfico de aplicación de la cobertura se encabeza por icono de un globo terráqueo, de color blanco sobre fondo azul o azul sobre fondo blanco.

La relativa a los riesgos excluidos irá encabezada por una $\mathrm{X}$ dentro de un triángulo que será de color blanco sobre fondo rojo o de color rojo sobre fondo blanco. La información sobre las principales exclusiones se expresará por un signo de exclamación de cierre (i) dentro de un triángulo, que será de color blanco sobre fondo naranja o de color naranja sobre fondo blanco. La referida a las obligaciones relativas al comienzo del contrato, durante su vigencia y en caso de solicitud de indemnización irá con el encabezamiento de un apretón de manos de color blanco sobre fondo verde o de color verde sobre fondo blanco. Los datos sobre las condiciones y la duración de los pagos irán encabezados por el icono de unas monedas y será de color blanco sobre fondo amarillo o color amarillo sobre fondo blanco. Si se trata de la duración del contrato el icono correspondiente será un reloj de arena que será de color blanco sobre fondo azul o azul sobre fondo blanco. Y la información sobre las modalidades de rescisión del contrato irá encabezada por un icono de una palma de la mano sobre un escudo de color blanco sobre fondo negro o de color negro sobre fondo blanco.

El documento podrá presentarse en papel o en un soporte duradero en cuyo caso podrá modificarse el tamaño de los componentes en la disposición de la página con la condición de que mantengan la disposición, los títulos y la secuencia previstos en el formato de presentación normalizado, así como el tamaño de los diversos elementos y los elementos destacados. Cuando las dimensiones del soporte duradero distinto del papel no permitan la disposición a dos columnas podrá utilizarse una disposición a una sola columna siempre que se respete una determinada

40 Como señala SOLÁ FERNÁNDEZ, F., El proceso precontractual..., cit., p. 81, se reconoce la capacidad del color para advertir o atraer la atención del consumidor sobre aspectos clave del producto y transmitir ideas intuitivas al cliente 
secuencia. ${ }^{41}$ También se permite el uso de herramientas digitales siempre que toda la información que se ha de proporcionar se facilite en el cuerpo principal del documento y que el uso de tales herramientas no permita distraer al consumidor del contenido principal del documento. Además, en tal caso no podrá incluir contenidos publicitarios o promocionales.

Como se verá más adelante, las notas informativas no deben proporcionarse cuando el producto de seguro distribuido sea de grandes riesgos, en línea con lo dispuesto con carácter general como exención de la obligación de información previa (art. 51 PLDSRP).

\subsection{Lenguaje y extensión}

El formato escogido trata de ser simple y fácil de entender, ordenado en apartados con preguntas y respuestas, en los que se va disponiendo el contenido, que ya concreta IDM II y se reproduce en el art. 50.3 del PLDSRP. El documento ha de reunir las siguientes características: brevedad y formulación individualizada, también claridad y fácil lectura. El lenguaje sencillo que exige el Reglamento 2017/1469 expresamente indica que se

41 a) «¿En qué consiste este tipo de seguro?»

b) «¿Qué se asegura?»

c) «¿Qué no está asegurado?»

d) «iExisten restricciones en lo que respecta a la cobertura?»

e) «¿Dónde estoy cubierto?»

f) «¿Cuáles son mis obligaciones?»

g) «¿Cuándo y cómo tengo que efectuar los pagos?»

h) «¿Cuándo comienza y finaliza la cobertura?»

i) «¿Cómo puedo rescindir el contrato?».

Por su parte, el art. 50. 4 del PLDSRP establece la siguiente secuencia:

4. El documento de información sobre el producto de seguro contendrá la siguiente información:

a) Información sobre el tipo de seguro.

b) Un resumen de las coberturas del seguro, incluidos los principales riesgos asegurados, la suma asegurada y, cuando proceda, el ámbito geográfico de aplicación, así como un resumen de los riesgos excluidos.

c) Las condiciones de pago de las primas, y la duración de los pagos.

d) Las principales exclusiones, sobre las cuales no es posible presentar solicitudes de indemnización.

e) Las obligaciones al comienzo del contrato.

f) Las obligaciones durante la vigencia del contrato.

g) Las obligaciones en caso de solicitud de indemnización.

h) La duración del contrato, incluidas las fechas de comienzo y de expiración.

i) Las modalidades de rescisión del contrato. 
evitará la "jerga especializada". Se requiere precisión en la información -se centrará en la información esencial que el cliente necesita para tomar una decisión con conocimiento de causa- que no ha de ser engañosa, e identificación como tal documento, que deberá aparecer en la parte superior de la primera página e inmediatamente a continuación debe indicarse el nombre del productor del seguro, el Estado miembro en que esté registrado el productor, su condición jurídica y, en su caso, su número de autorización. El productor podrá incluir su logotipo empresarial a la derecha del título. En caso de que el original se haya elaborado en color, no deberá perder claridad si se imprime o fotocopia en blanco y negro. Se redactará en las lenguas oficiales, o en una de las lenguas oficiales, utilizadas en la parte del Estado miembro en el que se distribuya el producto de seguro, o en otra lengua si así lo acuerdan el cliente y el distribuidor. El documento debe facilitarse en la forma elegida por el cliente, bien escrita, o en cualquier otra de carácter electrónico, siempre de manera gratuita al igual que toda la información precontractual ${ }^{42}$

El IPID es otro paso importante hacia la mejora de la confianza de los consumidores en los seguros y en el fortalecimiento de la protección al consumidor. El diseño propuesto ofrece la información clave sobre un producto de seguro de una manera clara y accesible. Los consumidores, que no suelen leer información precontractual extensa, ahora estarán facultados para comparar diferentes productos de seguros no vida, de una forma rápida y sencilla, sin necesidad de invertir mucho tiempo en su lectura. 


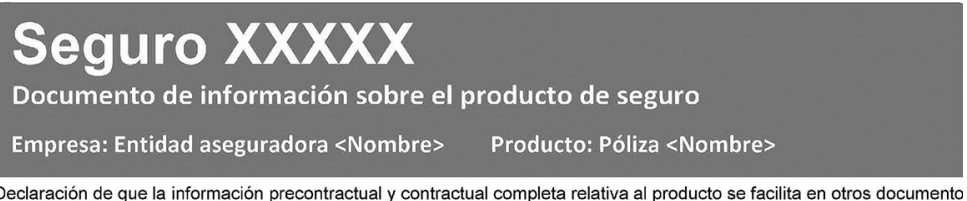

Jeclaración de que la información precontractual y contractual completa relativa al producto se facilita en otros documento En qué consiste este tipo de seguro?

Jescripción del seguro]

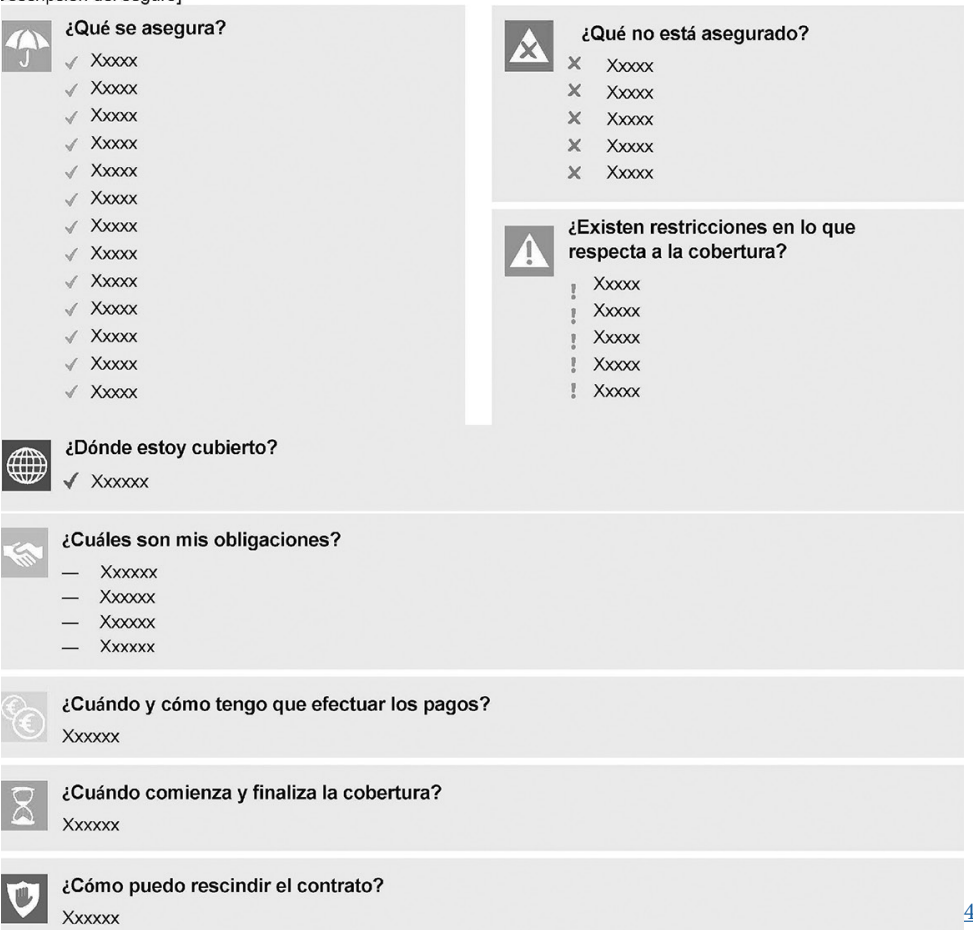

43 Anexo del REGLAMENTO DE EJECUCIÓN (UE) 2017/1469 DE LA COMISIÓN de 11 de agosto de 2017 por el que se establece un formato de presentación normalizado para el documento de información sobre productos de seguro.

Puede consultarse al respecto la Guía de buenas prácticas en el uso terminológico utilizado en el documento de información de productos de seguros no vida elaborada por la Asociación Empresarial del Seguros, UNESPA:

http://unespa-web.s3.amazonaws.com/main-files/uploads/2018/07/Guia-buenas-practicas-terminos-seguros-no-vida-FINAL.pdf 


\section{EXENCIÓN DE LA OBLIGACIÓN DE INFORMACIÓN PREVIA}

Los distribuidores de seguros dedicados a la colocación de grandes riesgos, que son aquellos a los que se refiere el art. 11 de la LOSSEAR, están exentos de los deberes de información formulados en los artículos precedentes. Ello implica que el denominado cliente profesional en atención a su experiencia, conocimientos y competencia para tomar sus propias decisiones en relación a los riesgos que asuma, carecen de un derecho a la información tan amplio como el predispuesto para el cliente normal. El PLDSRP considera a los clientes profesionales a aquellos que se contemplan en el art. 2.23 de este texto que reenvía al art. 78 bis.2, correspondiente al texto anterior de la Ley del Mercado de Valores. La referencia correcta debe entenderse realizada al art. 205 del TRLMV, aunque no entrará en vigor hasta el momento en que lo haga el RD que lo desarrolle, según establece la disposición final 5.2 del citado Real Decreto-ley 4/2018, de 28 de septiembre.

Aunque no se menciona de modo expreso en la norma -tampoco en IDM II-, se ha de considerar que también quedan exentos de esta obligación de información previa los corredores de reaseguro. No resulta en absoluto extraño que tanto los grandes riesgos como los corredores de reaseguro permanezcan ajenos al cumplimiento de este deber, si se tiene en cuenta que son dos sectores para los que se contemplan especialidades en otros ámbitos de la normativa aseguradora como la pérdida del carácter imperativo de las normas que regulan el contrato de seguro y las excepciones que se establecen en materia de protección del asegurado al no poder hacer la oportuna referencia al contratante débil, ya que estamos ante profesionales con grandes especialidades en relación al objeto asegurado.

\section{INCUMPLIMIENTO DE LA OBLIGACIÓN GENERAL DE INFORMAR}

En el capítulo de infracciones recogido en el art. 66 del PLDSRP y que forma parte del Capítulo VII sobre competencias de ordenación y 
supervisión, se establecen diversos tipos que encajan perfectamente con la situación que se está estudiando, trazando la responsabilidad administrativa de los distintos sujetos infractores relacionados con la actividad de distribución de seguros y que aparecen reflejados en el art. 65.1 del Proyecto.

En particular, la letra j) del apartado 2 de este art. 65 señala que tendrán la consideración de infracción muy grave la información inexacta o inadecuada a tomadores de seguro, a los asegurados, a los beneficiarios de las pólizas de seguro o, en su caso, a las entidades aseguradoras, siempre que por el número de afectados o por la importancia de la información tal incumplimiento pueda estimarse especialmente relevante. Por su parte, la letra 1) considera infracción muy grave el incumplimiento reiterado de las obligaciones de información y normas de conducta previstas en el capítulo VI del título II, cuando por la importancia de la información tal incumplimiento pueda estimarse especialmente relevante, respecto de productos de seguros distintos de los contemplados en la letra k), esto es, los productos de inversión basados en seguros.

En el apartado de las infracciones graves, la letra f) del aparatado 3 recoge el incumplimiento de las obligaciones de información y normas de conducta del capítulo VI del título II, cuando no concurran las circunstancias que se requieren para que se trate de una infracción muy grave respecto de productos que no sean de inversión basados en seguros.

A las infracciones muy graves se vincularán las sanciones previstas por el art. 68.1 del PLDSRP, muy semejantes a las previstas por la LMSRP, así para los mediadores de seguros se podrá proceder a la cancelación de las inscripciones en los correspondientes registros, así como la suspensión por un plazo máximo de 10 años para el ejercicio de su actividad; dar publicidad a la conducta constitutiva de la infracción muy grave, indicando quién es la persona física o jurídica responsable y cuál es la naturaleza de la infracción, así como a la sanción impuesta; multa por diversos importes, que dependerán de si se trata de una persona jurídica o una persona física quien comete la infracción, consistentes en tantos por ciertos del volumen de negocio o de los beneficios obtenidos o pérdidas evitadas o en una determinada cantidad de dinero. Puede añadirse incluso una amonestación privada. 
Igualmente, tal y como establece el art. 69, quien ejerza cargos de administración o bien sea responsable de la actividad de distribución o forme parte del órgano de dirección responsable de la actividad de distribución, será responsable de las infracciones muy graves o graves cometidas por los distribuidores de seguros o reaseguros y sociedades de correduría de reaseguros. En tales supuestos, podrá procederse a la separación del cargo con inhabilitación para ejercer cargos de administración o dirección en cualquier sociedad de distribución de seguros o reaseguros por un plazo no inferior a cinco años ni superior a diez; igualmente, podrá procederse a la suspensión temporal en el ejercicio del cargo por un plazo no inferior a un año ni superior a cinco años o una multa a cada uno de ellos por un importe máximo de 200.000 euros o, dependiendo de otras circunstancias valorables, se pueden rebajar los plazos y la cuantía de la multa, y dar publicidad a la conducta constitutiva de infracción y de la sanción impuestas o realizar una amonestación privada, para lo cual el art. 70 establece unos criterios para la graduación de las sanciones.

Se sigue manteniendo en todo caso la limitación de las sanciones aplicables a la conducta de los mediadores sin extensión de los posibles efectos del incumplimiento de la obligación de información en la relación contractual, lo que era ya uno de los aspectos más criticables de la LMSRP 44 ante el olvido del legislador.

\section{CONSIDERACIONES FINALES}

Si bien es cierto que algunos de los aspectos más novedosos y llamativos del PLDSRP - como la ampliación de su ámbito subjetivo- no están directamente relacionados con las obligaciones generales de información

44 Así, LATORRE CHINER, "Los deberes de información y asesoramiento del mediador de seguros", en CUÑAT EDO, V. y BATALLER GRAU, J (Dirs) Comentarios a la Ley de Mediación de Seguros y Reaseguros Privados, Thomson-Cívitas, 2007, Madrid, p. 222. Únicamente podrían calificarse como una excepción los casos en los que exista error o dolo como vicios del consentimiento, derivados de la inexistencia de esta información precontractual, en cuyo caso comportaría la anulabilidad del contrato según los arts. 1300 y ss del Código Civil. Vid., TIRADO SUÁREZ, F.J. y SARTI MARTÍNEZ, Ma A., La Ley de Mediación en Seguros y Reaseguros Privados. Comentarios a la Ley 26/2006, de 17 de julio de Mediación en Seguros y Reaseguros Privados. Legislación, Doctrina y Formularios, Thomson-Aranzadi, Navarra, 2007. pp. 618 y 619. 
dispuestas por la norma para los distribuidores de seguros, de una $\mathrm{u}$ otra forma, terminan confluyendo en ellas, como sucede con los sujetos obligados a informar y, por lo tanto, el régimen de la obligación de información previa dispuesto para las entidades aseguradoras, así como lo previsto en relación al asesoramiento que pueden realizar y a los posibles conflictos de interés, en particular, entre las empresas aseguradoras y sus empleados. También la necesidad de informar respecto a ciertas cuestiones como la relativa a la condición en la que actúan los intermediarios, en particular, los vínculos con las compañías aseguradoras y la remuneración a percibir por los vendedores de seguros.

En todo caso, uno de los objetivos fundamentales de IDM II, en línea con otras directivas y reglamentos que tratan de regular el sector financiero de un modo más amable para su consumidor, es fomentar la información que se le ha de proporcionar, una vez más, requiriendo un incremento de la misma, exigencia que ya se ha puesto de manifiesto que no alcanza su objetivo en la mayor parte de las ocasiones, ya que en muchas ocasiones esa información llega repetida por varias vías, con diferentes expresiones para referirse al mismo contenido o de distintas formas, lo que impide al cliente comprender qué se le está ofreciendo y peor aún qué es lo que está contratando en caso de que decida prestar su consentimiento, de ahí que se defienda la promoción de controles internos de los distribuidores para valorar la calidad de la información que proporcionan, así como su nivel de comprensión por parte de los clientes, acompañado del fortalecimientos de las oficinas o servicios de atención al cliente. $\underline{45}$

Sin embargo, en esta ocasión se quiere ensalzar el modo de haber afrontado el llamado documento de información previa o IPID, a través del Reglamento de ejecución (UE) 2017/1469 de 11 de agosto de 2017, por el que se establece un formato de presentación normalizado de dos páginas, tres a lo sumo, justificando esta ampliación. Consideramos que la estandarización de la presentación de la información junto con la utilización de iconos representativos de los datos que han de proporcionarse, constituye un interesante avance por su simplicidad y al tiempo por su exposición de conjunto relativamente breve, lo que va a impedir que el cliente se pierda ante los datos ofrecidos y pueda adoptar decisiones fundadas. Se cumple de este modo con un modo de proceder que consi- 
deramos de gran importancia en el ámbito de los mercados financieros como es la proporcionalidad de la información que se debe transmitir, en atención al tipo de producto que se ofrezca.

\section{BIBLIOGRAFÍA}

- AA VV, (2017). Insurtech, retos y desafíos de cara a la nueva distribución y contratación de seguros, RES, nº 169, 3 y ss.

- DÍAZ LLAVONA, C., (2012). Propuesta de revisión de la Directiva 2002/92/CE de mediación de seguros. Antecedentes, principales novedades y aspectos discutibles, RES, $\mathrm{n}^{\mathrm{o}} 150-151,245$ y ss.

- DÍAZ LLAVONA, C., (2017). Borrador de la futura ley de distribución de seguros: más allá de la mera transposición de la directiva. Algunas valoraciones jurídicas iniciales”, Diario La Ley, no 8951, de 29 de marzo de 2017, 1 y ss.

- GASCO ORTÍZ, A., (2018). Obligaciones de información y normas de conducta en el borrador de Anteproyecto de la Ley de distribución de seguros y reaseguros privados, La Ley Mercantil, n 46, 1 y ss.

- GIRGADO PERANDONES, P., (2016). Transparencia y deberes de información en la actividad profesional del mediador de seguros. A propósito de la nueva Directiva de Distribución de Seguros", La Ley Mercantil, no 21, 1 y ss.

- LATORRE CHINER, N., (2007). Los deberes de información y asesoramiento del mediador de seguros, en CUÑAT EDO, V. y BATALLER GRAU, J (Dirs) Comentarios a la Ley de Mediación de Seguros y Reaseguros Privados, Madrid: Thomson-Cívitas, 2007, pp. 221 y ss.

- MIRANDA SERRANO, L.M ${ }^{\mathrm{a}}$., (2017). Transparencia en la contratación de seguros: condiciones generales y particulares, RES, $n^{\circ}$ s. 171-172, $287 \mathrm{y}$ ss. 
- MUÑOZ PAREDES, J.Ma., (2017). La responsabilidad de los distribuidores en el Anteproyecto de Ley de Distribución, RES, nºs. 171-172, 361 y ss.

- PEÑAS MOYANO, M.J., (2017). Conductas de mercado, en: AAVV, Un derecho del seguro más social y transparente, en BATALLER GRAU, J., PEÑAS MOYANO, M. J., (Dirs), Cívitas Thomson Reuters, Madrid, pp. 755 y ss.

- PEÑAS MOYANO, M.J., (2017). El deber general de información de los aseguradores a los tomadores, asegurados y beneficiarios, RES, $\mathrm{n}^{\circ} \mathrm{s}$. $171-172,321$ y ss.

- QUINTÁNS EIRAS, Ma R., (2016). De la mediación a la distribución de seguros: la nueva Directiva 2016/1997. Revista General de Derecho Europeo, no 39, 1 y ss.

- QUINTANS EIRÁS, R., (2018). Información y conflicto de intereses en la comercialización de seguros, en: GIRGADO PERANDONES, P., (Dir), El contrato de seguro en la encrucijada, Madrid: Thomson Reuters Aranzadi, pp. 193 y ss.

- QUINTANS EIRÁS, R., (2018). Información como motor de la protección del asegurado en la comercialización de seguros, RES, $\mathrm{n}^{\circ} 175,373$ y ss.

- SÁNCHEZ SANTIAGO, J. y CID BLASCO, T., (2013). La nueva propuesta de Directiva de mediación de seguros y su impacto en el mercado español, Papeles de la Fundación, Fundación de Estudios Financieros, $\mathrm{n}^{\circ}$ 48,117 y ss.

- SIERRA NOGUERO, E., (2013). La remuneración del mediador de seguros en la propuesta de nueva directiva de mediación de seguros, en: QUINTÁNS EIRAS, Mª R., (Dir.), Estudios sobre Mediación de Seguros Privados, Madrid: Thomson Reuters Aranzadi, pp. 291 y ss.

- SOLÁ FERNÁNDEZ, F., (2017). El proceso precontractual en el contrato de seguro: nuevo marco jurídico, Cuadernos de la Fundación Mapfre, $n^{\circ} 220$. 
- TIRADO SUÁREZ, F.J. y SARTI MARTÍNEZ, Ma A., (2007). La Ley de Mediación en Seguros y Reaseguros Privados. Comentarios a la Ley 26/2006, de 17 de julio de Mediación en Seguros y Reaseguros Privados. Legislación, Doctrina y Formularios, Navarra: Thomson-Aranzadi.

\section{ABREVIATURAS}

- Autoridad Europea de Seguros y Fondos de Pensiones (EIOPA)

- Directiva 2002/92/CE del Parlamento Europeo y del Consejo, de 9 de diciembre, de 2002, sobre mediación en los seguros (IMD I)

- Directiva(UE) 2016/97 del Parlamento Europeo y del Consejo, de 20 de enero de 2016, sobre la distribución de seguros (versión refundida) (IMD II)

- Documento información previa (Insurance Product Information Document, IPID

- $\quad$ Ley 50/1980, de 8 de octubre, de Contrato de Seguro (LCS)

- $\quad$ Ley 27/2006, de 17 de julio, de Mediación de seguros y reaseguros privados (LMSRP)

- $\quad$ Ley 20/2015, de 14 de julio, de Ordenación, Supervisión y Solvencia de entidades aseguradoras y reaseguradoras (LOSSEAR)

- Directiva 2014/65/UE del Parlamento Europeo y del Consejo, de 15 de mayo de 2014, relativa a los mercados de instrumentos financieros y por la que se modifican la Directiva 2002/92/CE y la Directiva 2011/61/UE Texto pertinente a efectos del EEE (MiFID II)

- $\quad$ Proyecto de Ley de Distribución de Seguros y Reaseguros Privados 121/000022, de 21 de mayo de 2018 (PLDSRP)

- Productos preempaquetados de inversión minorista (PRIPs) 
- Reglamento (UE) no 1286/2014 del Parlamento Europeo y del Consejo de 26 de noviembre de 2014 sobre los documentos de datos fundamentales relativos a los productos de inversión minorista vinculados y los productos de inversión basados en seguros (Texto pertinente a efectos del EEE) (Reglamento PRIPs)

- $\quad$ Real Decreto Legislativo 4/2015, de 23 de octubre, por el que se aprueba el Texto refundido de la Ley del Mercado de Valores (TRLMV) 